\begin{tabular}{c} 
Volume and Issues Obtainable at Center for Sustainability Research and Consultancy \\
Sustainable Business and Society in Emerging Economies \\
ISSN: $2708-2504$ (E): 2708-2172 \\
Volume 2: No 1, June 2020 \\
CSRE \\
Journal homepage: $\underline{\text { ww.publishing.globalcsrc.org/sbsee }}$ \\
\hline
\end{tabular}

\title{
Attitude, Perceived Behavioral Control and Subjective Norm in Waste Segregation- at-Source Behavior: An Empirical Study
}

\author{
${ }^{1}$ Kai Wah Cheng \\ ${ }^{1}$ Graduate Research Fellow, Department of Resource Management and Consumer Studies, Faculty of \\ Human Ecology, Universiti Putra Malaysia, Malaysia. chengkaiwah1991@gmail.com
}

\begin{tabular}{l}
\hline ARTICLE DETAILS \\
\hline History \\
Revised format: May 2020 \\
Available Online: June 2020 \\
\\
\hline Keywords \\
Attitude, \\
Perceived Behavioral \\
Control, \\
Subjective Norm, \\
Waste Segregation-at-Source \\
Behavior. \\
\hline
\end{tabular}

JEL Classification: $M 0, M 1$

\begin{abstract}
Purpose: The aim of this paper is to assess the level and relationship between attitude, perceived behavioral control and subjective norm with waste segregation-at-source behavior among households in Putrajaya, Malaysia.
\end{abstract}

Design/Methodology/Approach: A multi-stage sampling method used to obtain four hundred households in Putrajaya for the purpose of responding to the bilingual questionnaire. The quantitative data collected were analyzed using the IBM SPSS Version 26.0 software. Specifically, the descriptive and Pearson correlation analysis used to describe and summarize the levels and interrelationships of the variables studied with waste segregation-at-source behavior.

Findings: The assessment of the overall factors affecting households with waste segregation-at-source behavior has shown that 92.5 per cent of respondents are considered to have a favorable attitude. Households surveyed are also found to be highly influenced by perceived behavioral control but moderately influenced by the subjective norm. In addition, the results show that attitudes, perceived behavioral control and subjective norm have a positive relationship with waste segregation-atsource behavior.

Implications/Originality/Value: The findings provide insight, in particular, to individual, governmental, educational and nongovernmental organizations in Malaysia on important criteria that should be considered in the promotion of environmental policies.

(C) 2020 The authors, under a Creative Commons AttributionNonCommercial 4.0

Corresponding author's email address: chengkaiwah1991@gmail.com

Recommended citation: Cheng, K.W. (2020). Attitude, Perceived Behavioral Control and Subjective Norm in Waste Segregation-at-Source Behavior: An Empirical Study. Journal of Business and Social Review in Emerging Economies, 2(1), 83-93

\section{Introduction}

There has been considerable concern about solid waste management issues (Otitoju \& Seng, 2014) as a key step towards a clear understanding of waste segregation-at-source, a policy that was recently launched by the Malaysian Ministry of Housing and Local Government in 2015. Issues associated with solid waste 
management in developing countries cannot be over-emphasized (Amuda, Adebisi, Jimoda, \& Alade, 2014). Large amounts of municipal solid waste exert enormous and significant additional pressures on the existing number of human health hazards (Seth, Cobbina, Asare, and Duwiejuah, 2014), including the spread of communicable diseases, nuisances, bad odors and serious adverse environmental consequences of water, air and soil contamination (Lim, 2012), if the waste is not managed in a proper manner. Furthermore, in Southeast Asian cities, including Malaysia, proper and efficient municipal solid waste management should be given the utmost attention to building a "zero waste" society and systematically managing the solid waste generated. Ideally, waste management is an essential public health service (Addoyobo \& Ali, 2003) which basically encompasses a series of management activities, namely the collection, transport, landfilling, recycling and composting of solid waste materials (Miafodzyeva, Brandt, \& Andersson, 2013) in a manner that is environmentally compatible with the standards that best encompass the consideration of energy, environment conservations, aesthetics, health and economics.

Besides that, the increasing number of solid waste landfills in the country has also stimulated all Malaysian consumers to reflect on the importance of finding a balance between the systematic management of their solid waste and the pattern of consumption to improve health and well-being at the same time. Indeed, the landfill is considered to be one of the cheapest methods of disposal of solid waste. Land-filling is thus commonly used as a final disposal destination for solid waste (Malik, Abdullah, \& Abd Manaf, 2015). As such, the United Nations Development Program (2014) claimed that most of the landfill sites in Malaysia had already reached their maximum capacity and could no longer be able to accommodate the amount of waste generated. Approximately 75.0 per cent of the waste is disposed of in landfills and dumps (Kalanatarifard \& Yang, 2012). An estimated 20.0 per cent is burned or dumped in rivers or illegal sites, which include open dump sites where illegal dumping takes place or where a large quantity of garbage has accumulated. However, only about 5.0 per cent of the waste is recycled (Tam, Soomro, \& Evangelista, 2018). Although the government has been promoting recycling programs in Malaysia since 1993, it cannot be considered a very successful program due to lukewarm attitudes and lack of household participation (Aja, \& Al-Kayiem, 2014).

For this reason, the proper handling of municipal solid waste is important in order to reduce negative environmental, economic and social impacts. The best way to manage waste generation is therefore to reduce waste at source (Sawitri, Hadiyanto, \& Hadi, 2015), i.e. to eliminate waste generation at source and to recycle or reuse waste materials.

\section{Literature Review}

\subsection{Attitude and Waste Segregation-at-Source Behavior}

Literature of attitude variable is still scarce in waste segregation-at-source behavior, as a relatively small number of discussions have so far focused on it. However, environmental attitudes and psychological and situational variables have been seen as important predictors of recycling behavior. A wide range of successful studies on general ecological behavior, as well as on the recycling of housing (Babaei, Alavi, Goudarzi, Teymouri, Ahmadi, \& Rafiee, 2015; do Valle \& Assaker, 2016; Nigbur, Lyons, \& Uzzell, 2010) were conducted based on the attitude variable.

Environmental attitudes have been presented as a key component and indicator of environmental behavior (Cheng \& Osman, 2017). Favorable attitudes will help individuals to play a significant role in environmental conservation (Vodouhe, Coulibaly, Adegbidi, \& Sinsin, 2010). A survey of 382 households living in Putrajaya reveals that positive attitude on solid waste segregation-at-source will encourage a high level of participation by the local community in the recycling program (Malik et al., 2015). Accordingly, the current researcher assumed that people with strong pro-environmental attitudes are more likely to engage in proenvironmental behavior.

On the other hand, environmental attitudes have also been described as having a varying and very slight effect on environmental behavior, because people tend to live according to their own values. This can be 
justified by one of the studies carried out by Han, Hwang, Kim, and Jung (2015) on causal relationships and environmental behavior, in which attitudes have been observed to have a significant effect on the representation of pro-environmental behavior. Conversely, this statement clearly contradicts the view of Boer and Fischer (2013) that attitudes are inconsistent with human behavioral intentions, as the motivations for expressing one attitude may differ from the underlying expression of another person.

The links between the environmental behavior and households' attitude are complex, but they are well connected to externalizing problems. Research on waste disposal in people's minds and attitudes towards waste segregation-at-source are included in the scheme of official development plans (Osman, Jusoh, Amlus, \& Khotob, 2014), but they have not been adequately considered and have therefore led to a recent upsurge in waste disposal problems in developing countries. Attitudes, on the other hand, can indirectly influence pro-environmental behavior. In a study conducted by Murad and Siwar (2007) among secondary school students in Kuala Lumpur City, the findings showed that these female students had a high level of favorable attitudes towards the environment but a moderate level of environmental protection behavior. More specifically, female students tend to have higher positive attitudes towards environmental protection compared to male students.

Attitudes between households on generated waste can have a significant impact on their willingness to cooperate and participate in waste segregation-at-source behavior (Otitoju \& Seng, 2014). Attitudes are highly nurtured by a citizen's sense of responsibility. The public is therefore expected to prioritize their responsibilities in environmental care in order to enhance their personal well-being and the well-being of their families (Fah \& Sirisena, 2014). The motivation to develop environmentally friendly behavior, therefore, increases when pro-environmental behavior is aligned with these personal priorities. However, the desired behaviors are less likely to be adopted if they contradict the priorities. In this situation, the study emphasized that the residents strongly believe that new technologies and methods will be developed in order to find a more friendly solution to the problems of waste segregation-at-source, particularly involving waste generators, in order to separate their recyclables from the waste generation site in order to improve their own well-being as well as their own well-being.

\subsection{Perceived Behavioral Control and Waste Segregation-at-Source Behavior}

To the best of knowledge, there is no specific research that focuses primarily on waste segregation-at-source behavior by using perceived behavioral control as a predictor that has been identified in Malaysia (Masud, Al-Amin, Junsheng, Ahmed, Yahaya, Akhtar, \& Banna, 2016). The ongoing challenges in the long-term implementation of waste segregation-at-source behavior in Malaysia still require a broader and clearer picture of the current scenario in order to increase the efficiency and effectiveness of this policy. As a result, this research has assumed that it has become necessary to explore the impact of perceived behavioral control on waste segregation-at-source behavior among Malaysian citizens.

One behavioral arena that has received more research attention than most is the management of household waste. Household waste generation is a growing concern in the developing and developed world (Lebreton \& Andrady, 2019). More importantly, individual belief and perception (Zamani-Farahani, \& Musa, 2012) will influence the response, cultural values and success of the municipal solid waste management system. Nor can it be denied that the impact of perceived community-based behavioral control on waste segregationat-source behavior is essential to the assessment of how to improve municipal solid waste management in order to manage, mitigate and prevent excess waste that has been disposed of in landfills, thereby prolonging the lifespan of the landfill (Wang, Maier, Horn, Hollander, \& Aschemann, 2018).

The extent to which the current waste issue is perceived as a tangible threat to personal well-being is seen as an important determinant of environmental and waste management behavior. Clayton, Devine-Wright, Swim, Bonnes, Steg, Whitmarsh, and Carrico (2016) criticized the view that environmental issues should be perceived as a threat to health and well-being, since they override many traditional predictors of environmental behavior. Thus, in this circumstance, Graham-Rowe, Jessop, and Sparks (2019) stressed that 
there would be a tangible relationship between the degree to which individuals perceive the waste issue as crucial and the consequent behavioral response. It may be location or personal experience, such as living in an area where it refuses to pose a risk to public health or in the vicinity of a landfill site, as it may provide an incentive to manage waste more carefully.

Many people felt that their individual actions could not have any significant impact on a given issue or task. This situation can generally be linked to any arena of social behavior, but it seems more vividly to the environmental aspect, where global warming is linked to individual actions by reducing the use of cars, conserving energy and reducing waste. Steinemann, Geelan, Zaehringer, Mutuura, Wolkow, Frasseck, and Opwis (2020) reported that the degree to which a given behavior would be undertaken to have a tangible effect. Citizens who believed that their actions could make any significant difference to waste issues were those who were more likely to act. The present researcher therefore assumed that the efficacy of this response is likely to prove decisive in promoting environmentally sound behavior from an individualistic perspective.

Ultimately, current research has assumed that Malaysian citizens should not overemphasized their own ability to segregate solid waste at source as their daily routine. As a recap, perceived behavioral control refers to people's perceptions as to whether they can demonstrate that specific behavior and how easy it is to demonstrate in life. As a result, they should feel motivated as they have the appropriate opportunities, resources and skills to practice waste segregation-at-source positively. In this case, they will no longer feel any difficulty or inconvenience while performing the ideal behavior that is likely to occur.

\subsection{Subjective Norm and Waste Segregation-at-Source Behavior}

In terms of research-based discussion, although there is still a lack of existing research showing that subjective norms act as predictors for the determination of waste segregation-at-source behaviour, while there are still a number of research studies that have recognized that subjective norms can be associated with different research disciplines, including climate change issues (Masud et al., 2016), cosmetic product purchasing behavior (Haque, Anwar, Tarofder, Ahmad, \& Sharif, 2018), transport mode choice (Eriksson \& Forward, 2011), waste recycling behavior (Matthies, Selge, \& Klockner, 2012), energy conservation (Macovei, 2015), and non-compliant behavior (Goh, Ritchie, \& Wang, 2017).

Multiple research (Goh et al., 2017; Macovei, 2015; Ahmad, Juhdij, Jasin, \& Saidon, 2009) have shown that subjective norm is the strongest predictor followed by attitude. Indeed, respondents acknowledged that the recycling behavior of their referents is a very important step in shaping their own recycling behavior. Ahmad et al. (2009) examined the influence of role model; family members, close friends, celebrity endorses young female consumers and their intention to purchase cosmetic products. The findings have showed that there is a significant influence on the role model of women consumers in the purchasing behavior of cosmetic products.

Ajzen and Fishbein (1980) have pointed out that recycling behaviors can be changed when individuals are aware of the social norm and, more importantly, accept the norm. This statement is closely linked to the concept of a subjective norm in which the power of influence acts on an individual to perform an ideal behavior based on the approval and support of their important social groups (Ajzen, 1991). The same concern arises from Trudel (2019) who discovered that the awareness of other people who are acting to recycle will shape the behavior of others. This can be further justified by the recycling behavior of Hong Kong residents, who are highly influenced by the subjective norm as they play their part in motivating and encouraging other residents to engage in recycling on a daily basis (Armitage \& Conner, 2001).

In short, it is very clear that the subjective norm plays an important role in inculcating the behavior of recycling. Accordingly, in this research, it is estimated that the degree to which the subjective norm variable is also an essential link in fostering the re-use and resource-reduction behavior, including waste segregationat-source behavior, is considered to be an interesting aspect, as this behavior is much less visible to 
individuals and the public.

\section{Research Methodology}

Putrajaya has been chosen as a research location on the basis of of its own unique criteria for the practice of waste segregation-at-source behaviour since it was chosen as the "Pioneer Township in Green Technology" showcase in 2010. Putrajaya also intended to be transformed into a Low Carbon Society by 2025 (Hashim, Hashim, \& Shuib, 2017). In order to carry out this research, a multi-stage sampling method was used to reach four hundred households living in Putrajaya. Data were collected from citizens in Putrajaya using self-administrated questionnaires that performed the daily routine of waste segregation-atsource behavior. Four hundred valid and usable responses were submitted for further analysis of the data. A total response rate of hundred per cent has been achieved in this research, as researchers and field assistants have assisted all respondents throughout the data collection process. The data collected were then analyzed using IBM SPSS Statistics Software Version 26.0. Both descriptive and inferential statistics were used for data analysis. For this reason, statistical analysis, in particular descriptive analysis and Pearson correlation analysis were used to analyze the data.

\section{Results and Discussion}

\subsection{Respondent's Socio-Demographic and Socio-Economic Information}

Data were collected from a total of four hundred respondents, comprising 40.3 per cent of male and 59.8 per cent of female households. However, 48.3 per cent of male citizens and 55.5 per cent of female citizen in Putrajaya were among the 103800 citizens in 2019. In other words, the sex ratio found in this study did not accurately reflect the sex ratio in Putrajaya. (Department of Statistics Malaysia, 2020).

The mean age of the respondents was 33.6 years old and the median age was 32.0 years old. The youngest and oldest of the samples were 17 and 64 years old, respectively. 39.5 per cent of the age of the respondent ranged from 22 to 31 . Only two respondents were over 61 years old, while 18 of the respondents were between 52 and 61 years old. As a result, the continuation of the Malaysia's aging population can be shown by the median age of population, which increased from 23.6 years old in 2000 (Department of Statistics Malaysia, 2015) to 28.9 years old in 2019 (Department of Statistics Malaysia, 2019), was consistent with the sample in this research which is 32.0 years old.

In this research, the Bumiputera respondents appeared to be the largest group in the sample (93.8\%). The distribution of the Chinese and Indian groups was followed by a percentage of 3.5 per cent and 2.3 per cent respectively. Similarly, the ethnic composition found in this research did not reflect the ethnic composition of Malaysia. In Malaysia, there was a total population of 32.6 million people, 90.18 per cent of whom were citizens of Malaysia and 9.82 per cent of whom were non-citizens. Malaysia citizens include Bumiputera (69.3\%), Chinese (22.8\%), Indians (6.9\%) and others (1.0\%) (Department of Statistics Malaysia, 2019).

Moreover, the Population Distribution and Basic Demographic Characteristic Report 2010 which updated in May 2015 revealed that the population aged 15 years and above who were never married was 35.1 per cent, while those who were married was 59.6 per cent. In this research, however, respondents who were never married were 59.3 per cent, while those who were married were 39.8 per cent.

With respect to the highest education qualification of respondents, 33.5 per cent of respondents were found to have at least a bachelor's degree in education. A minority of the households $(3.5 \%)$ found that they had an LCE/SRP/PMR/PT3 academic qualification. The remaining households were found to have secondary qualifications of MCE/SPM/SPM (V) (22.3\%), Certificate/HSC/STP/STPM (21.8\%), Diploma (14.8\%) and Master or Ph.D. (4.3\%) in particular. In the category of occupation, the largest group of respondents $(22.8 \%)$ were categorized as service and sales workers, followed by 20.8 per cent of professionals, 15.5 per cent of clerical support workers and 14.0 per cent of elementary occupations. A minority of respondents $(3.8 \%)$ were identified as senior officials and managers.

\subsection{Levels of Studied Variables with Waste Segregation-at-Source Behavior}


Table 1 shows the frequency and percentage of respondents' attitudes towards waste segregation-at-source behavior that are grouped into a favorable or unfavorable category of attitudes (Rahmaddin, Hidayat, Yanuwiadi, \& Suyadi, 2015). Using the medium split method (Der-Karabetian, Cao, \& Alfaro, 2014), the unfavorable attitude ranged from a minimum score of 10 to 27, while the favorable attitude ranged from 28 to a maximum score of 43. The mean and standard deviation for the variable of attitude are 32.67 and 34.00 respectively. Overall, a large group of households in Putrajaya $(92.5 \%)$ have a favorable attitude. However, 7.5 per cent of households have an unfavorable attitude to waste segregation-at-source behavior in Putrajaya. As a result, under this circumstance, the results can be concluded that most individuals are classified into the favorable attitude category and have a positive attitude to waste segregation-at-source behavior.

In the case of perceived behavioral control, the mean value for perceived behavioral control was 32.06 with a standard deviation of 5.42. A total of 12 respondents $(3.0 \%)$ were perceived to have a low level of perceived behavioral control on waste segregation-at-source. Subsequently, 46.7 per cent and 50.3 per cent of respondents were identified as moderate and high levels of perceived behavioral control respectively. Consequently, this result means that there was a higher percentage of respondents $(50.3 \%)$ in Putrajaya who were perceived to have a high level of perceived behavioral control over their behavior towards waste segregation-at-source.

From the point of view of the subjective norm, its mean value was 22.07 with a standard deviation of 4.61. Seven per cent of respondents were perceived to have a low level of subjective norm towards waste segregation-at-source behavior. Subsequently, 66.5 per cent and 26.5 per cent of respondents were identified at moderate and high levels of subjective norm respectively. In other words, this result means that there is a higher percentage of the households surveyed $(66.5 \%)$ who live in Putrajaya had a moderate level of subjective norm with waste segregation-at-source behavior.

Table 1: Levels of Studied Variables with Waste Segregation-at-Source, $\mathbf{N}=400$

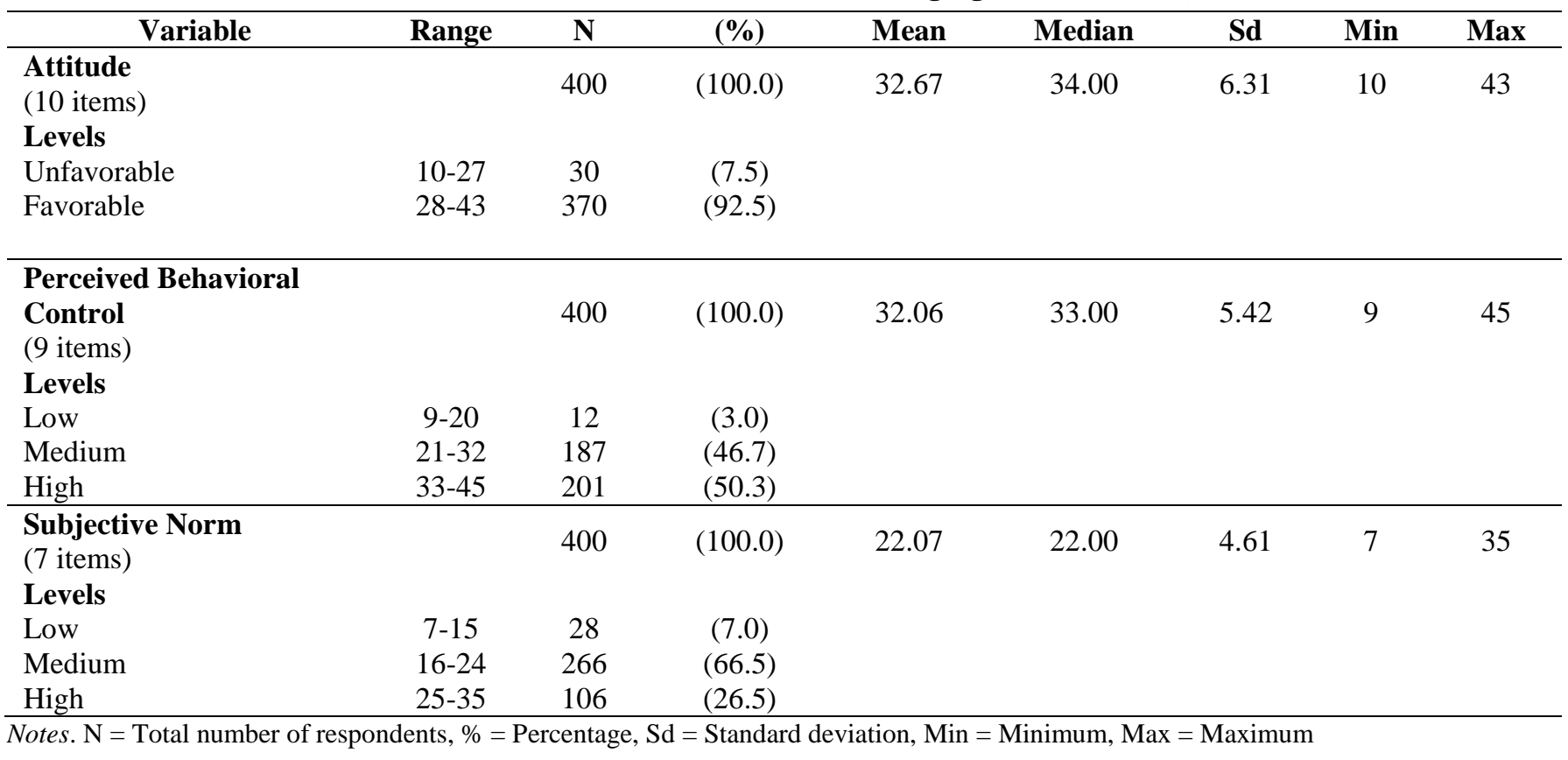

\subsection{Relationships between Studied Variables and Waste Segregation-at-Source Behavior}

Table 2 shows the Pearson correlation analysis with respect to the relationship between the selected variables and the waste segregation-at-source behavior. The results showed that two independent variables (attitude and perceived behavioral control) had a positive significant relationship with the dependent variable (waste segregation-at-source behavior). More specifically, there was a positive significant 
relationship of attitude in the prediction of waste segregation-at-source behavior at a 0.05 level (two-tailed) as denoted by $p=0.001(p<0.01)$ and $r=0.168$. For the $p$-value, if there is a value less than 0.01 , there is always a significant relationship between the independent variable and the dependent variable.

Besides that, based on the outputs shown in Table 2, the results show that there is a significant relationship between perceived behavioral control and waste segregation-at-source behavior, as denoted by $p=0.000$ $(p<0.01)$ and $r=0.301$. The value of the correlation coefficient $(r)$ will show the strength of the significance of this relationship. According to Cohen, Cohen, West, and Aiken (2003), the $r$-value ranged from 0.30 to 0.49 is considered to be a moderate relationship. In the context of this research, the $r$-value of this relationship is 0.301 ; therefore, the strength of this significant relationship is considered to be a moderate relationship. Meanwhile, positive $r$-value shows that the relationship between perceived behavioral control and waste segregation-at-source behavior was a positive relationship. This means that if households have more experience of the influence of perceived behavioral control, their role in understanding environmentally friendly behavior will be easier to play (Paul, Modi, \& Patel, 2016).

Table 2: Pearson Correlations between the Studied Variables and Waste Segregation-at-Source Behavior,

$$
\mathrm{N}=400
$$

\begin{tabular}{lcc}
\hline \multicolumn{1}{c}{ Variable } & Waste Segregation-at-Source Behavior \\
& $\boldsymbol{r}$-value & $\boldsymbol{p}$-value \\
\hline Attitude & $0.168^{* *}$ & 0.001 \\
Perceived behavioural control & $0.301^{* *}$ & 0.000 \\
Subjective norm & 0.080 & 0.110 \\
\hline
\end{tabular}

Notes. ** Correlation is significant at the 0.01 level (2-tailed)

In the meantime, there is also an examination of the correlation between the subjective norm and the waste segregation-at-source behavior. However, there is an insignificant relationship at a 0.05 level (two-tailed) between the subjective norm and the waste segregation-at-source behavior $[(r=0.080, \mathrm{p}=0.110(p>0.05)]$. It is surprising to note that the findings of this current research were completely different from those of previous research (Chen \& Chao, 2011; Cherian \& Jacob, 2012). The pro-environmental behavior of adolescents (e.g. the reduction of electricity, the responsible handling of waste and the purchase of ecofriendly products) depends mainly on the dominant norms in their families, as reflected in parental behavior. As a result, there is a reason to describe the significant relationship between the subjective norm and the waste segregation-at-source behavior. Miliute, Hage, Plepys, and Reipas (2016) also conducted a survey of 714 samples in their research to prove that the subjective norm is the most important determinant of household recycling behavior in the recycling scheme.

\section{Conclusions and Implications}

The results of this research indicated that there were a substantial number of households $(92.5 \%)$ with a favorable attitude (28-43) to waste segregation-at-source behavior. This is because most of the respondents were very concerned and interested in the concept of waste segregation-at-source behavior. The relevance of this outcome is clearly underpinned by recent findings (Rahmaddin et al., 2015; Jekria \& Daud, 2016).

Next, in the light of the results of this research, it was found that there was a high level of perceived behavioral control (33-45) among households in Putrajaya. More than half of the households in Putrajaya $(50.3 \%)$ agree that they should use any item that is reusable and recyclable again. However, 50.2 per cent of households were still unsure about how to segregate their household waste. Local government should therefore be more alert to this percentage distribution in order to increase awareness among citizens of the importance and benefits of this policy, which in turn reduces environmental degradation.

However, the subjective norm played a moderate role (16-24) in influencing households involved in research to portray waste segregation-at-source behavior on a daily basis. In this research, 40.8 per cent of 
households agreed that family members played an important role in encouraging respondents to segregate their solid waste. Parents are therefore role models, as they observe and imitate educational efforts to encourage their children to practice this habit.

The findings of this research also detailed that there is a significant relationship between attitude and waste segregation-at-source behavior among households in Putrajaya. This means that the influence of attitude plays a significant role to perform the waste segregation-at-source behavior among the respondents. Similarly, this research also found a significant correlation between perceived behavioral control and waste segregation-at-source behavior. However, it was interesting to note that the variable of subjective norm is not significant for the waste segregation-at-source behavior in this research. The findings of this research are therefore expected to have practical implications and to be used as a reference by policy makers in developing countries such as Malaysia.

From the point of view of the non-governmental organization, the Waste Management Association of Malaysia can potentially benefit from these research findings by formulating workable community activities. They can organize a number of related awareness-raising programs and instill a sense of responsibility to protect the cleanliness of the environment among households in Putrajaya. This research also encourages cooperation and collaboration between all concerned and interested persons in waste management. Workshops, seminars, trainings and relevant courses on waste management can be held on a regular basis for the welfare and benefit of the stakeholders.

Consumers can also benefit from this research findings, as this research provides a platform for them to learn about environmental knowledge, which in turn will become a knowledgeable consumer and improve their ability to empower themselves to protect the environment for future generations. This is because environmental knowledge can lead to the creation and enhancement of public awareness, knowledge and participation in waste segregation-at-source in local communities, school children and the public.

Finally, Pearson correlation analysis in this study suggested that perceived behavioral control, followed by attitude and subjective norm, are relatively important variables in predicting waste segregation-at-source behavior. This scenario therefore shows that households should be able to recognize the importance of being environmentally friendly in order to ensure that they behave in an ecologically favorable manner. Previous research by Simpson and Radford (2012) has shown that consumer environmentally compatible behavior can be motivated by an emphasis on the importance of environmental issues. In line with that, the marketing perspective is another conspicuous managerial implication for this research. Marketers should communicate to the target community that they conduct pro-environmental behaviors which, in turn, have a significant impact on the well-being of the environment. Through a well-targeted advertising campaign, marketers can encourage positive attitudes and behaviors of environmentally friendly people. As a result, consumers will also feel good about depicting waste segregation-at-source behavior that is less harmful to the environment.

\section{References}

Addo-Yobo, F. N. \& Ali, M. (2003). Households: Passive users or active managers? The case of solid waste management in Accra, Ghana. International Development Planning Review, 25(4), 373-389.

Ahmad, S. N. B., Juhdij, N., Jasin, D., \& Saidon, J. (2009). Consumer ethnocentrism and influence of role model on young female purchase intentions towards cosmetic product. The Business Review, Cambridge, 13(2), 170-199.

Aja, O. C. \& Al-Kayiem, H. H. (2014). Review of municipal solid waste management options in Malaysia, with an emphasis on sustainable waste-to-energy options. Journal of Material Cycles and Waste Management, 16(4), 693-710.

Ajzen, I. \& Fishbein, M. (1980). Understanding Attitudes and Predicting Social Behavior. Englewood Cliffs: Prentice-Hall.

Ajzen, I. (1991). The Theory of Planned Behavior. Organizational Behavior and Human Decision Processes, 50, 179-211. 
Amuda, O. S., Adebisi, S. A., Jimoda, L. A., \& Alade, A. O. (2014). Challenges and possible panacea to the municipal solid wastes management in Nigeria. Journal of Sustainable Development Studies, 6(1), 64-70.

Armitage, C. J. \& Conner, M. (2001). Efficacy of the theory of planned behaviour: A meta-analytic review. British Journal of Social Psychology, 40(4), 471-499.

Babaei, A. A., Alavi, N., Goudarzi, G., Teymouri, P., Ahmadi, K., \& Rafiee, M. (2015). Household recycling knowledge, attitudes and practices towards solid waste management. Resources, Conservation and Recycling, 102, 94-100.

Boer, D., \& Fischer, R. (2013). How and when do personal values guide our attitudes and sociality? Explaining cross-cultural variability in attitude-value linkages. Psychological Bulletin, 139(5), 1113.

Chen, C. F. \& Chao, W. H. (2011). Habitual or reasoned? Using the theory of planned behavior, technology acceptance model, and habit to examine switching intentions toward public transit. Transportation Research Part F: Traffic Psychology and Behavior, 14(2), 128-137.

Cheng, K. W. \& Osman, S. (2017). Waste segregation behaviour at source: Attitude, perceived behavioural control, subjective norm, and environmental education. Malaysian Journal of Consumer, 29(1), 118.

Cherian, J. \& Jacob, J. (2012). Green marketing: A study of consumers' attitude towards environment friendly products. Asian Social Science, 8(12), 117-126.

Clayton, S., Devine-Wright, P., Swim, J., Bonnes, M., Steg, L., Whitmarsh, L., \& Carrico, A. (2016). Expanding the role for psychology in addressing environmental challenges. American Psychologist, 71(3), 199.

Cohen, J., Cohen, P., West, S. G., \& Aiken, L. S. (2013). Applied Multiple Regression/Correlation Analysis for the Behavioral Sciences. London: Lawrence Erlbaum Associates.

Department of Statistics Malaysia. (2015). Population Distribution and Basic Demographic Characteristic Report 2010 (Updated: 05/08/2011). Retrieved on August 14 ${ }^{\text {th }}, 2020$ from https://www.dosm.gov.my/v1/index.php?r=column/ctheme\&menu_id=L0pheU43NWJwRWVSZk IWdzQ4TlhUUT09\&bul_id=MDMxdHZjWTk1SjFzTzNkRXYzcVZjdz09

Department of Statistics Malaysia. (2019). State Socioeconomic Report 2018. Retrieved on August 14 ${ }^{\text {th }}$, 2020 https://www.dosm.gov.my/v1/index.php?r=column/cthemeByCat\&cat=102\&bul_id=a0c3UGM3 MzRHK1N1WGU5T3pQNTB3Zz09\&menu_id=TE5CRUZCblh4ZTZMODZIbmk2aWRRQT09

Department of Statistics Malaysia. (2020). Pocket Stats Q1 2020. Putrajaya: Malaysian Prime Minister's Department.

Der-Karabetian, A., Cao, Y., \& Alfaro, M. (2014). Sustainable behavior, perceived globalization impact, world-mindedness, identity, and perceived risk in college samples from the United States, China, and Taiwan. Ecopsychology, 6(4), 218-233.

do Valle, P. O. \& Assaker, G. (2016). Using partial least squares structural equation modeling in tourism research: A review of past research and recommendations for future applications. Journal of Travel Research, 55(6), 695-708.

Eriksson, L. \& Forward, S. E. (2011). Is the intention to travel in a pro-environmental manner and the intention to use the car determined by different factors?. Transportation Research Part D: Transport and Environment, 16(5), 372-376.

Fah, L. Y. \& Sirisena, A. (2014). Relationships between the knowledge, attitudes, and behaviour dimensions of environmental literacy: A structural equation modeling approach using smartpls. Jurnal Pemikir Pendidikan, 5, 119-144.

Goh, E., Ritchie, B., \& Wang, J. (2017). Non-compliance in national parks: An extension of the theory of planned behaviour model with pro-environmental values. Tourism Management, 59, 123-127.

Graham-Rowe, E., Jessop, D. C., \& Sparks, P. (2019). Self-affirmation theory and pro-environmental behaviour: Promoting a reduction in household food waste. Journal of Environmental Psychology, 62, 124-132.

Han, H., Hwang, J., Kim, J., \& Jung, H. (2015). Guests' pro-environmental decision-making process: 
Broadening the norm activation framework in a lodging context. International Journal of Hospitality Management, 47, 96-107.

Haque, A., Anwar, N., Tarofder, A., Ahmad, N., \& Sharif, S. (2018). Muslim consumers' purchase behavior towards halal cosmetic products in Malaysia. Management Science Letters, 8(12), 1305-1318.

Hashim, S. F., Hashim, H., \& Shuib, K. B. (2017). Resident perspective on cycling as an option for transportation in Putrajaya. Planning Malaysia: Journal of the Malaysian Institute of Planners, 15(2), 97-108.

Jekria, N. \& Daud, S. (2016). Environmental concern and recycling behaviour. Procedia Economics and Finance, 35, 667-673.

Kalanatarifard, A. \& Yang, G. S. (2012). Identification of the municipal solid waste characteristics and potential of plastic recovery at Bakri Landfill, Muar, Malaysia. Journal of Sustainable Development, 5(7), 11.

Lebreton, L. \& Andrady, A. (2019). Future scenarios of global plastic waste generation and disposal. Palgrave Communications, 5(1), 1-11.

Lim, M. (2012). Measuring waste in Malaysia: A neglected approach. Procedia-Social and Behavioral Sciences, 42, 198-204.

Macovei, O. I. (2015). Applying the theory of planned behavior in predicting proenvironmental behaviour: The case of energy conservation. Acta Universitatis Danubius. Economica, 11(4), 15-32.

Malik, N. K. A., Abdullah, S. H., \& Abd Manaf, L. (2015). Community participation on solid waste segregation through recycling programmes in Putrajaya. Procedia Environmental Sciences, 30, 1014.

Masud, M. M., Al-Amin, A. Q., Junsheng, H., Ahmed, F., Yahaya, S. R., Akhtar, R., \& Banna, H. (2016). Climate change issue and theory of planned behaviour: relationship by empirical evidence. Journal of Cleaner Production, 113, 613-623.

Matthies, E., Selge, S., \& Klockner, C. A. (2012). The role of parental behaviour for the development of behaviour specific environmental norms-The example of recycling and re-use behaviour. Journal of Environmental Psychology, 32(3), 277-284.

Miafodzyeva, S., Brandt, N., \& Andersson, M. (2013). Recycling behaviour of householders living in multicultural urban area: A case study of Jarva, Stockholm, Sweden. Waste Management and Research, 31(5), 447-457.

Miliute, P. J., Hage, O., Plepys, A., \& Reipas, A. (2016). What motivates households recycling behaviour in recycling schemes of different maturity? Lessons from Lithuania and Sweden. Resources, Conservation and Recycling, 113, 40-52.

Murad, W. \& Siwar, C. (2007). Waste management and recycling practices of the urban poor: A case study in Kuala Lumpur city, Malaysia. Waste Management and Research, 25(1), 3-13.

Nigbur, D., Lyons, E., \& Uzzell, D. (2010). Attitudes, norms, identity and environmental behaviour: Using an expanded theory of planned behaviour to predict participation in a kerbside recycling programme. British Journal of Social Psychology, 49(2), 259-284.

Osman, A. D. B. A., Jusoh, M. S., Amlus, M. H., \& Khotob, N. (2014). Exploring the relationship between environmental knowledge and environmental attitude towards pro-environmental behaviour: Undergraduate business students perspective. American-Eurasian Journal of Sustainable Agriculture, 8, 1-7.

Otitoju, T. A. \& Seng, L. (2014). Municipal solid waste management: Household waste segregation in Kuching South City, Sarawak, Malaysia. American Journal of Engineering Research (AJER), 3(6), 82-91.

Paul, J., Modi, A., \& Patel, J. (2016). Predicting green product consumption using theory of planned behavior and reasoned action. Journal of Retailing and Consumer Services, 29, 123-134.

Rahmaddin, M. Y., Hidayat, T., Yanuwiadi, \& Suyadi, B. (2015). Knowledge, attitude, and action of community towards waste management in river bank of Martapura. International Journal of Applied Psychology, 5(4), 96-102.

Sawitri, D. R., Hadiyanto, H., \& Hadi, S. P. (2015). Pro-environmental behavior from a social cognitive theory perspective. Procedia Environmental Sciences, 23, 27-33. 
Seth, K., Cobbina, S. J., Asare, W., \& Duwiejuah, A. B. (2014). Household demand and willingness to pay for solid waste management service in Tuobodom in the Techiman-North District, Ghana. American Journal of Environmental Protection, 2(4), 74-78.

Simpson, B. J. \& Radford, S. K. (2012). Consumer perceptions of sustainability: A free elicitation study. Journal of Nonprofit and Public Sector Marketing, 24(4), 272-291.

Steinemann, S. T., Geelan, B. J., Zaehringer, S., Mutuura, K., Wolkow, E., Frasseck, L., \& Opwis, K. (2020). Potentials and pitfalls of increasing prosocial behavior and self-efficacy over time using an online personalized platform. Plos One, 15(6), e0234422.

Tam, V. W., Soomro, M., \& Evangelista, A. C. J. (2018). A review of recycled aggregate in concrete applications (2000-2017). Construction and Building Materials, 172, 272-292.

Trudel, R. (2019). Sustainable consumer behavior. Consumer Psychology Review, 2(1), 85-96.

United Nations Development Program. (2014). Human Development Report 2014. Sustaining Human Progress: Reducing Vulnerability and Building Resilience. New York: United Nations Development Program.

Vodouhe, F. G., Coulibaly, O., Adegbidi, A., \& Sinsin, B. (2010). Community perception of biodiversity conservation within protected areas in Benin. Forest Policy and Economics, 12(7), 505-512.

Wang, J., Maier, S. D., Horn, R., Hollander, R., \& Aschemann, R. (2018). Development of an ex-ante sustainability assessment methodology for municipal solid waste management innovations. Sustainability, 10(9), 3208.

Zamani-Farahani, H., \& Musa, G. (2012). The relationship between Islamic religiosity and residents' perceptions of socio-cultural impacts of tourism in Iran: Case studies of Sare'in and Masooleh. Tourism Management, 33(4), 802-814. 